\title{
DINÂMICA DE UMA COMUNIDADE ARBÓREA APÓS ENCHENTE EM FRAGMENTOS FLORESTAIS NO SUL DE MINAS GERAIS ${ }^{1}$
}

\author{
Ana Carolina da Silva², Eduardo van den Berg ${ }^{3}$, Pedro Higuchi ${ }^{4}$ e Matheus Henrique Nunes $^{5}$ \\ RESUMO - Com o objetivo de avaliar o impacto de uma enchente de grandes proporções sobre os indivíduos \\ arbóreos, foi realizada, no ano de 2007, a avaliação de uma área aluvial localizada em São Sebastião da Bela \\ Vista, MG, onde foram amostrados cinco fragmentos aluviais e uma floresta ciliar, inventariados inicialmente \\ em 2005. Os resultados indicaram que, após a enchente, a dinâmica no curto-prazo foi caracterizada por taxa \\ de mortalidade superior à de recrutamento e taxa de perda maior do que a de ganho em área basal. Entretanto, \\ a estrutura da comunidade não foi alterada, pois a frequência de indivíduos sobreviventes e de mortos nas \\ classes diamétricas foi proporcional ao número inicial de indivíduos em cada classe. Os resultados permitiram \\ concluir que, apesar de não terem sido observadas alterações na estrutura diamétrica, a dinâmica da comunidade \\ arbórea refletiu o distúrbio causado pela enchente.
}

Palavras-chave: Dinâmica florestal, Distúrbios naturais e Fragmentos florestais.

\section{TREE COMMUNITY DYNAMIC AFTER FLOODING IN FOREST FRAGMENTS IN SOUTHERN MINAS GERAIS, BRAZIL}

\begin{abstract}
In order to evaluate the impact of a catastrophic flooding on tree individuals, it was carried out, in 2007, evaluation of an alluvial area in São Sebastião da Bela Vista, MG, where it was sampled five alluvial fragments and a riparian forest, which was inventoried in 2005. Results show that after the flooding, a short-term dynamics was characterized by a mortality rate higher than recruitment rate and loss rate was higher than gain rate in basal area. However, the structure of the community was not affected, because frequency of surviving and dead trees in the diametric classes was proportional to the initial number of individual in each class. The results allowed to conclude that although there was no alteration in the diametric structure, the tree community dynamics reflected the disturbance caused by the flooding.
\end{abstract}

Keywords:Forest dynamic, Forest fragment and Natural disturbances.

\section{INTRODUÇÃO}

No mês de janeiro de 2007, a pluviosidade na Região Sudeste do Brasil excedeu a dos anos anteriores, ocasionando enchentes em diversos municípios. No Sul de Minas Gerais, o extravasamento do rio Sapucaí ocasionou a inundação de florestas ciliares e da planície aluvial adjacente ao rio. Desde 1998, quando vários municípios foram afetados, não havia ocorrência de uma enchente como esta na região.
Entre os locais intensamente afetados pela enchente estão as áreas aluviais inventariadas por Silva et al. (2009), em São Sebastião da Bela Vista, Minas Gerais, no mês de julho de 2005. Apesar de a região possuir sistemas de drenos e diques construídos pelo projeto Pró-Várzea na década de 1970 para evitar as inundações na planície aluvial, como incentivo à agricultura, estes não foram suficientes para conter essa inundação. Esse evento representou uma boa oportunidade para avaliação da dinâmica no curto prazo da comunidade arbórea

\footnotetext{
${ }^{1}$ Recebido em 30.12.2008 e aceito para publicação em 20.04.2011.

${ }^{2}$ Universidade do Estado de Santa Catarina, UDESC, Brasil. E-mail: <carol_sil4@yahoo.com.br>.

${ }^{3}$ Departamento de Biologia, Universidade Federal de Lavras, UFLA, Brasil. E-mail: <eduardo.lavras@gmail.com>.

${ }^{4}$ Universidade do Estado de Santa Catarina, UDESC, Brasil. E-mail: <higuchip@gmail.com>.

${ }^{5}$ Escola Superior de Agricultura "Luiz de Queiroz" - Universidade do Estado de São Paulo, ESALQ - USP, Brasil: E-mail: $<$ mhnunes@usp.br>.
} 
pós-distúrbio, uma vez que estudos que avaliam a dinâmica de florestas inundáveis (e.g. GUILHERME et al., 2004; GUIMARÃES et al., 2008) e o efeito de enchentes catastróficas (e.g. APPOLINÁRIO et al., 2005; DAMASCENO-JUNIOR et al., 2004) não são comuns no centro-sul do Brasil. Esses estudos são importantes, pois permitem o monitoramento e a previsão dos processos de transformação de populações e comunidades vegetais pós-distúrbio natural ou antrópico (SHEIL et al., 2000; GOMES et al., 2004).

Enchentes de grandes proporções ou catastróficas são eventos raros e, por essa razão, podem causar desequilíbrio em ecossistemas adaptados a um regime hídrico mais ou menos constante de inundações e períodos secos. Esses eventos podem ter considerável efeito na estrutura de florestas que margeiam os rios (DAMASCENO-JUNIOR et al., 2004) e contribuem para a existência de grandes heterogeneidades ambiental espacial e temporal observada em ambientes aluviais (BRINSON, 1990).

Este trabalho teve como principal objetivo avaliar a dinâmica em curto prazo da comunidade arbórea de fragmentos aluviais e de uma floresta ciliar no Sul e Minas Gerais após a enchente catastrófica ocorrida em janeiro de 2007. Na comparação com dados coletados na mesma região em 2005, serão verificados se houve aumento na mortalidade de indivíduos arbóreos, perda em área basal e alteração na estrutura diamétrica da comunidade arbórea.

\section{MATERIAL E MÉTODOS}

\subsection{Descrição da área de estudo}

Foram estudados um fragmento de floresta ciliar e cinco fragmentos florestais na planície aluvial localizados no Município de São Sebastião da Bela Vista, Minas Gerais (entre $22^{\circ} 05^{\prime} 57^{\prime \prime S}$ a $22^{\circ} 07^{\prime} 22,5^{\prime \prime S}$ e 4548'05"W a 4548'53,5"W; altitude de 809 m). A região está localizada na Bacia Hidrográfica do Rio Sapucaí, que integra a Bacia do Rio Grande, com relevo predominante entre o plano e o suave-ondulado, e as formas planas estão sujeitas às inundações periódicas.

No rio Sapucaí, além da floresta ciliar, existem vários fragmentos florestais naturais e antrópicos, que estão localizados em matriz de vegetação herbácea associada a solos com condições de saturação hídrica inviáveis ao estabelecimento de vegetação arbórea. Nas partes mais elevadas do relevo, o grau de saturação hídrica diminui e há o estabelecimento do componente arbóreo, formando, assim, ilhas em meio a áreas mais saturadas. Os solos da região são, predominantemente, Neossolos, nas florestas ciliares, Gleissolos, nas áreas de maior encharcamento e Cambissolos, nas áreas menos saturadas (SILVA et al., 2009).

Na região são observadas enchentes de diferentes intensidades durante a época das chuvas, e no ano de 2007 ocorreu enchente de maiores proporções, afetando tanto a floresta ciliar como os fragmentos. Conforme observado no campo após a enchente e relatos de moradores, as árvores na floresta ciliar e nos fragmentos 1, 3, 4 e 5 ficaram submersas, com a água em diferentes alturas nos troncos. $\mathrm{O}$ fragmento 2 foi menos afetado pela enchente, por estar em local um pouco mais elevado no terreno. Além da submersão, a floresta ciliar foi afetada pela correnteza da enchente por estar na calha principal do rio. No entanto, conforme observado por Silva et al. (2010) o encharcamento nos fragmentos pode se estender por meses, devido aos solos mais argilosos e maldrenados, ao contrário da floresta ciliar, cuja drenagem é mais rápida devido ao solo arenoso. Nas medições da altura do nível freático no solo, realizadas de dois em dois meses durante um ano (segundo semestre de 2005 e primeiro de 2006) por Silva et al. (2010) nas mesmas parcelas, foi encontrado o nível freático acima da superfície do solo em algumas parcelas dos fragmentos durante o período de aproximadamente sete meses. Nas parcelas dos fragmentos onde o nível freático se encontrava a poucos centímetros abaixo da superfície do solo, o período de maior encharcamento também durou aproximadamente sete meses. A água só recuou nesses fragmentos nos meses de junho a outubro. Na floresta ciliar, em nenhum mês foi encontrado o nível freático próximo à superfície do solo ou acima deste, demonstrando que, quando ocorrem enchentes, estas recuam rapidamente, não sendo possível, na frequência em que foram feitas as medições, observar nível freático próximo à superfície do solo nesse setor.

Segundo a classificação de Köppen, o clima predominante na região é mesotérmico úmido, com dois a três meses secos ao ano, enquadrado no tipo Cwb (temperatura média do mês mais frio inferior a $18^{\circ} \mathrm{C}$ e do mês mais quente não ultrapassa $22^{\circ} \mathrm{C}$ ) (BRASIL, 1992). O índice pluviométrico anual está entre 1.300 e $1.700 \mathrm{~mm}$, com o período seco nos meses de junho 
a agosto, e mais chuvoso de dezembro a fevereiro (50\% da pluviosidade anual). A umidade relativa do ar varia entre 70 e $82 \%$ durante o ano, sendo os valores mais baixos observados nos meses de junho a agosto. A região Sul mineira enquadra-se em zona de influência dos domínios vegetacionais do cerrado e da floresta atlântica (RIZZINI, 1997), e as florestas da área de estudos são classificadas, de acordo com a classificação do IBGE (1992), como Floresta Estacional Semidecidual Aluvial.

\subsection{Amostragem da vegetação}

Os estudos de dinâmica foram conduzidos em 54 parcelas de $200 \mathrm{~m}^{2}(10 \times 20 \mathrm{~m})$, correspondentes às alocadas, em 2005, no estudo fitossossiológico de Silva et al. (2009). Dessas, 24 parcelas foram alocadas na floresta ciliar, sendo nove na borda do rio, nove na borda na matriz de campo circundante e seis no interior da floresta ciliar. Em cada um dos cinco fragmentos aluviais estudados, seis parcelas foram analisadas, sendo três na borda e três no interior, com exceção do Fragmento 5, onde todas as parcelas se localizavam na borda ou próxima a ela, devido ao seu tamanho reduzido e formato alongado (SILVA et al., 2009).

No estudo de Silva et al. (2009), todos os indivíduos arbóreos vivos dentro das parcelas que apresentaram diâmetro medido a 1,30 m de altura (DAP) igual ou superior a $5 \mathrm{~cm}$ foram identificados e mensurados (DAP e altura), em julho de 2005. Indivíduos com caules múltiplos foram medidos quando a soma das áreas basais das secções dos caules correspondia a uma área basal igual ou superior à de um caule único com 5 cm de DAP.

Em julho de 2007, seis meses após a enchente (mesmo intervalo utilizado por DAMASCENO-JÚNIOR, 2004), foi realizado o segundo inventário da comunidade arbórea, utilizando-se a mesma metodologia do inventário anterior. Nesse inventário foram incorporados os novos indivíduos que atingiram o DAP $\geq 5 \mathrm{~cm}$, registrados os indivíduos mortos e mensurados os sobreviventes.

\subsection{Dinâmica da comunidade arbórea}

Foram calculadas as taxas de mortalidade e recrutamento e as taxas de ganho e perda em área basal, com base no número de indivíduos e área basal, por meio dos modelos algébricos descritos por Sheil e May (1996). A taxa média anual de rotatividade em número de árvores (Rotn) foi calculada pela média das taxas de mortalidade e de recrutamento, e a taxa média anual de rotatividade em área basal (Rotab) foi calculada pela média de taxa de perda e taxa de ganho (KORNING; BALSLEV, 1994; OLIVEIRA-FILHO et al., 1997). As mudanças líquidas para o número de indivíduos (Cn) e para a área basal ( $C a b)$ e as taxas de mudança líquida para o número de indivíduos ( $C h n$ ) e para a área basal (Chab) foram calculadas por equações descritas por Korning e Balslev (1994).

As taxas de dinâmica da comunidade arbórea foram comparadas entre a floresta ciliar e fragmentos pelas análises de variância não paramétrica de Kruskal-Wallis, realizadas no programa Statistica (STATSOFT, 2001).

\subsection{Dinâmica por classe diamétrica}

As taxas de dinâmica por classe de diâmetro foram analisadas na amostra da área total e dos fragmentos, empregando-se intervalos de classe com amplitudes crescentes (5,0-8,9 cm, classe 1; 9,0-16,9 cm, classe 2; 17,0-32,9 cm, classe 3; 33-64,9 cm, classe 4; e $\geq 65 \mathrm{~cm}$, classe 5), para compensar o declínio em densidade nas classes de tamanhos maiores, típico da distribuição J-invertido.

Em cada classe de diâmetro foi contabilizado o número de árvores mortas, ingressantes (indivíduos recrutados e vindos de outras classes de diâmetro) e egressantes (indivíduos que migraram para outras classes de diâmetro), podendo os dois últimos ser progressivos ou regressivos (LIEBERMAN et al., 1985). As diferenças entre as proporções de árvores ingressantes (recrutas + imigrantes) e árvores egressas (mortos + emigrantes) em cada classe de diâmetro para os fragmentos, a floresta ciliar e a amostra total foram verificadas por meio do teste binomial (SOKAL; ROHLF, 1994), feito no programa R (R DEVELOPMENT CORE TEAM, 2005). As diferenças entre as classes de árvores mortas e recrutas, em toda a comunidade, a floresta ciliar e os fragmentos, independentemente de classe diamétrica, também foram avaliadas pelo mesmo teste.

Com base na distribuição de diâmetros em 2005, foram utilizados testes G (SOKAL; ROHLF, 1994) para verificar se as frequências de árvores vivas em 2007 e de árvores mortas foram independentes das classes de diâmetro, sendo as análises realizadas no programa R (R DEVELOPMENT CORE TEAM, 2005).

Revista Árvore, Viçosa-MG, v.35, n.4, xxx-xxx, 2011 


\section{RESULTADOS}

\subsection{Dinâmica da comunidade arbórea}

Entre os anos de 2005 e 2007, houve declínio no número de indivíduos arbóreos e decréscimo na área basal da área total (Tabela 1). Durante esse período, a taxa de mortalidade $\left(2,21 \% \mathrm{ano}^{-1}\right)$ foi superior à taxa de recrutamento $\left(0,90 \% \mathrm{ano}^{-1}\right)$, resultando em perda líquida de $1,32 \%$ ano $^{-1}$ no número de indivíduos.

O decréscimo em área basal, demonstrado pela taxa de mudança líquida da área basal entre os anos inventariados, foi de $-0,60 \% \mathrm{ano}^{-1}$. A perda em área basal devido à mortalidade de indivíduos $\left(1,1001 \mathrm{~m}^{2}\right)$ correspondeu aproximadamente ao dobro do ganho em área basal em função do recrutamento e crescimento dos sobreviventes $\left(0,5631 \mathrm{~m}^{2}\right)$, o que explica as diferenças entre as taxas de perda $\left(2,92 \% \mathrm{ano}^{-1}\right)$ e de ganho em área basal $\left(2,34 \% \mathrm{ano}^{-1}\right)$.

A dinâmica da comunidade arbórea apresentou heterogeneidade entre os fragmentos estudados nas taxas de mortalidade, de ganho em área basal e de rotatividade em número de indivíduos e área basal (Tabela 1). Apesar de estar mais sujeita ao impacto do distúrbio da enchente, pois nela a água da enchente passou em grande velocidade devido à correnteza do rio, a floresta ciliar não apresentou a maior taxa de mortalidade $\left(2,47 \%\right.$ ano $\left.^{-1}\right)$. Essa foi observada nos fragmentos 3 e 4 , com as médias de 2,67\% ano ${ }^{-1}$ e $5,59 \%$ ano $^{-1}$, respectivamente $(p=0,0510)$. As taxas de recrutamento foram baixas e não diferiram significativamente entre os fragmentos estudados.

A floresta ciliar e os fragmentos 3 e 4 seguiram o mesmo padrão observado na área total em relação ao maior número de árvores mortas que de recrutas (Tabela 2). Em toda a área foram encontradas 90 árvores mortas e 36 recrutas $\left(p<10^{-4}\right)$, na floresta ciliar foram contabilizadas 29 árvores mortas e 14 recrutas ( $p=0,0315)$, no fragmento 3 foram encontradas 18 mortas e quatro recrutas ( $p=0,0043$ ) e no fragmento 4 houve 28 indivíduos mortos e nove recrutas $(p=0,0026)$. Nos fragmentos $1(p=0,5078), 2(p=1,000)$ e 5 ( $p=0,6250)$, o número de árvores mortas foi igual ao de recrutas.

A área basal, quando analisada separadamente por fragmento, reduziu-se na floresta ciliar e nos fragmentos 3 e 4, manteve-se praticamente estável no fragmento 2 e aumentou pouco nos fragmentos 1 e 5
(Tabela 1). Porém, as taxas de perda em área basal não apresentaram diferenças significativas entre os fragmentos ( $p=0,1044)$, ao contrário das taxas de ganho em área basal, que diferiram significativamente $(p=0,0076)$. O fragmento 4 apresentou a maior taxa média de ganho em área basal (3,75\% ano ${ }^{-1}$, Tabela 1$)$, consequência não somente do maior recrutamento, mas, principalmente, do maior crescimento das sobreviventes. A maior rotatividade média da área basal foi também encontrada nesse fragmento: $4,67 \% \mathrm{ano}^{-1}(p=0,0097$, Tabela 1).

\subsection{Dinâmica da comunidade por classe diamétrica}

Na área total, o número de ingressos foi diferente do número de egressos apenas nas classes diamétricas $1(p=0,0364)$ e $4(p=0,0386)$ (Tabela 2$)$. Ambas as classes possuíram maior número de egressos, representados, na classe 1 , pela migração para outras classes (50 indivíduos foram para a classe 2) e mortalidade (41 mortos) dos indivíduos. Na classe 4 houve influência, principalmente, do decremento em diâmetro (dos oito egressos, seis foram para a classe 3 ), causado, em grande parte das vezes, pela mortalidade de alguns troncos de árvores perfilhadas (observação de campo).

Na análise separada por fragmento, não houve diferenças significativas $(p<0,05)$ entre o número de ingressos e egressos em nenhuma classe diamétrica para a floresta ciliar, fragmento 2 e fragmento 5 (Tabela 2). No fragmento 1 houve diferença somente na classe 2 ( $p=0,0213$ ), com 13 indivíduos egressos (10 emigrantes, dos quais seis migraram para a classe 1 e quatro para a classe 3 e três mortos) e três indivíduos ingressos. No fragmento 3 , somente a primeira classe $(p=0,0060)$ apresentou diferenças entre egressos (26 indivíduos, dos quais 12 mortos e 14 emigrantes) e ingressos (nove indivíduos, dos quais quatro recrutas e cinco imigrantes). O fragmento 4 obteve grande número de egressos na primeira classe, sendo 19 mortos e 12 emigrantes, diferindo dos ingressos ( $p=0,0029)$, nove recrutas e dois imigrantes.

Essas mudanças não influenciaram a estrutura da comunidade como um todo, pois o padrão de distribuição diamétrica dos indivíduos arbóreos não diferiu significativamente, pelo teste G, entre 2005 e 2007, na amostra total $(p=0,8262)$, na floresta ciliar $(p=0,9271)$ e nos fragmentos $1,2,3,4$ e $5(p=0,868$, $p=0,7464, p=0,8945, p=0,6252, p=0,8210$, respectivamente). O número de indivíduos mortos 


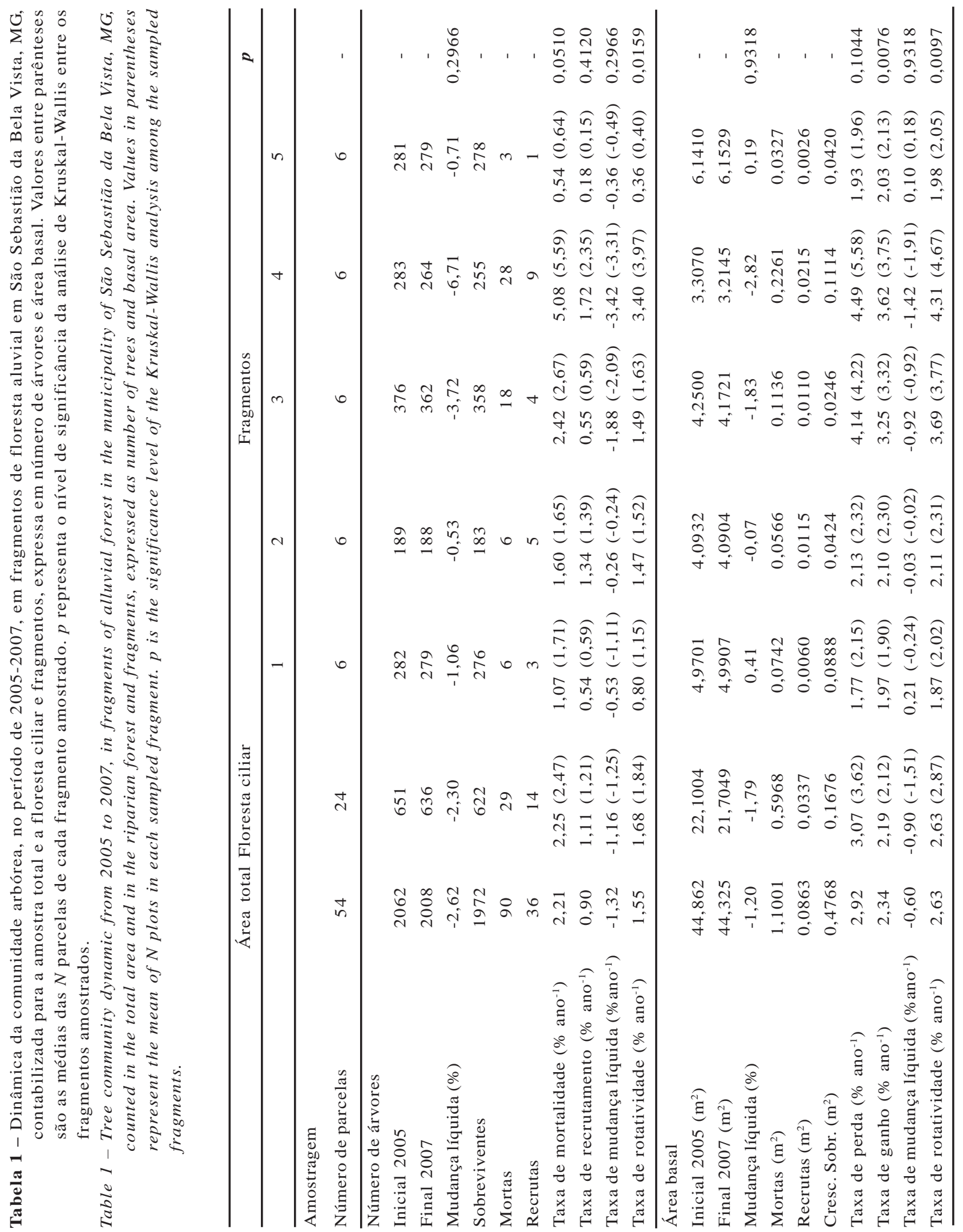




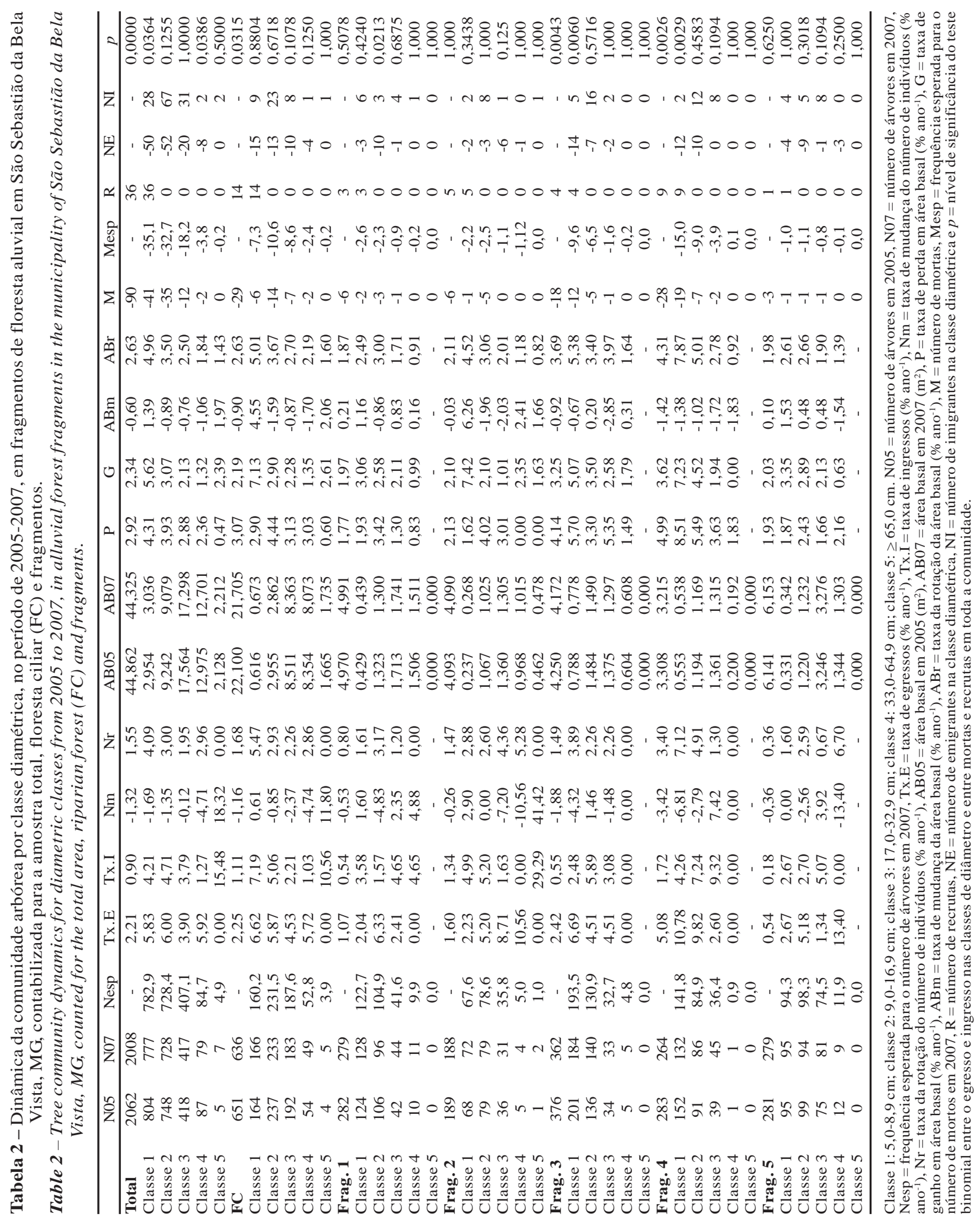

Revista Árvore, Viçosa-MG, v.35, n.4, p.883-893, 2011 
observados também não diferiu, pelo teste $\mathrm{G}$, do número de indivíduos mortos esperados nas classes de diâmetro, na área total $(p=0,2864)$, na floresta ciliar $(p=0,7366)$ e nos fragmentos $1,2,3,4$ e $5(p=0,7366$, $p=0,2522, p=0,7934, p=0,6037$ e $p=0,9895$, respectivamente).

\section{DISCUSSÃO}

\subsection{Dinâmica da comunidade arbórea}

Os resultados indicaram instabilidade na dinâmica da área estudada, pois o padrão esperado na dinâmica de florestas não perturbadas em avançado estágio de sucessão é de equilíbrio entre as taxas de ganho/perda e recrutamento/mortalidade (LIEBERMAN et al., 1985; SWAINE et al., 1987), o que não foi observado neste estudo.

De acordo com relatos de moradores locais, a enchente deixou as árvores da floresta ciliar e do fragmento 1 parcialmente submersas, sendo os setores mais afetados pela enchente. No fragmento 1, algumas parcelas estavam com grande parte das placas das árvores retiradas pela água, sendo encontrados nesse fragmento restos de peixes, trazidos pela enchente. Esses impactos poderiam explicar os maiores valores encontrados neste estudo de mortalidade de indivíduos e perda em área basal do que os de recrutamento e ganho.

Além disso, o padrão da dinâmica do número de indivíduos encontrado neste estudo diferiu daqueles observados em fragmentos de florestas não aluviais na região do Sul de Minas Gerais. Nessas florestas existe a tendência ao maior equilíbrio entre as taxas de mortalidade e de recrutamento, como exemplo: taxa de mortalidade de $2,56 \%$ ano $^{-1}$ e taxa de recrutamento de $2,99 \%$ ano $^{-1}$ no estudo de Oliveira Filho et al. (1997) em Lavras, taxa de mortalidade de $2,5 \%$ ano $^{-1}$ e taxa de recrutamento de $1,8 \%$ ano $^{-1}$ no estudo de Oliveira Filho et al. (2007) em Piedade do Rio Grande, taxa de mortalidade de $1,8 \%$ ano $^{-1}$ e taxa de recrutamento de 1,4\% ano $^{-1}$ no estudo Higuchi et al. (2008a) em Lavras e taxa de mortalidade de $3,15 \%$ ano $^{-1}$ e taxa de recrutamento de 2,28\% ano ${ }^{-1}$ no estudo de Machado e Oliveira-Filho (2010) em Lavras. Outro estudo de Higuchi et al. (2008b) em floresta não aluvial em Lavras demonstrou padrões diferenciados entre os quatro períodos estudados, porém, com predominância de taxas de recrutamento, que variaram de $1,64 \%$ a 3,29\%, e de mortalidade, que variaram de 2,33\% a 4,61\%, com tendência ao equilíbrio. Esses resultados reforçam a ideia de maior instabilidade na dinâmica de comunidades arbóreas em ambientes aluviais do que em ambientes não alagáveis.

Outros estudos, que realizaram análises das taxas de mortalidade e do ganho em área basal em áreas alagáveis e não alagáveis adjacentes, demonstram maior mortalidade nas áreas alagáveis e variação nos padrões das taxas de ganho. Appolinário et al. (2005), comparando a dinâmica de uma área inundável à de uma área adjacente, de topografia mais elevada, não inundável, encontraram maior taxa de mortalidade de árvores nas áreas inundáveis e taxas de ganho mais acelerado nos sítios não inundáveis. Guilherme et al. (2004), comparando área inundável com área de encosta, de menor tempo e, ou, nenhuma inundação, também encontraram maior taxa de mortalidade na área inundável. Porém, esses autores encontraram maior ganho da área basal na área inundável, contrariando os resultados encontrados por Appolinário et al. (2005), o que pode ser explicado pelo rápido crescimento das espécies de grande dominância na área de estudo com maior tempo de inundação: Salix humboldtiana Willd. e Inga vera Willd.

Além dos efeitos causados pela inundação, as taxas de mortalidade neste estudo podem estar relacionadas a fatores antrópicos em alguns fragmentos. As maiores taxas de mortalidade observadas nos fragmentos 3 e 4 podem ser explicadas, por exemplo, pela maior frequência de distúrbios antrópicos observados: corte seletivo de alguns indivíduos, principalmente da espécie Rollinia emarginata Schltdl. O fragmento 4 foi o que possuiu também a maior rotatividade média do número de indivíduos. Provavelmente, a intensa exploração desse fragmento ao longo do tempo colaborou para esses resultados. O corte seletivo resulta em abertura de clareiras que, por disponibilizarem maior quantidade de luz, podem ocasionar o crescimento de espécies iniciais, que possuem o crescimento e mortalidade mais acelerados, explicando também a maior taxa de ganho em área basal, devido ao crescimento das sobreviventes, e a maior taxa de rotatividade da área basal nesse fragmento. A maior taxa de ganho em área basal em áreas perturbadas foi encontrada também por Oliveira-Filho et al. (1997) e associada à composição de espécies iniciais, de rápido crescimento.

A taxa de recrutamento de toda a área $\left(0,90 \% \mathrm{ano}^{-1}\right)$ esteve abaixo dos valores encontrados nos outros trabalhos em florestas inundáveis: $1,28 \%$ ano $^{-1}$ no estudo

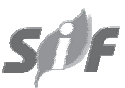

Revista Árvore, Viçosa-MG, v.35, n.4, xxx-xxx, 2011 
de Guimarães et al. (2008), 1,28\% ano ${ }^{-1}$ e 2,00\% ano ${ }^{-1}$ nas florestas na área de depressão e sobre o dique, respectivamente, estudadas por Guilherme et al. (2004) e 2,1\% ano ${ }^{-1}$ na área estudada por Appolinário et al. (2005). Neste estudo, é possível que a enchente ocorrida em janeiro de 2007 tenha inibido o recrutamento, por meio da mortalidade ou estagnação no crescimento de indivíduos menores que $5 \mathrm{~cm}$ de DAP. Segundo Junk (1993), associada às inundações, ocorre deposição periódica de sedimentos, fator limitante ao estabelecimento das plantas. Em enchentes de grandes proporções, quando comparadas com enchentes mais brandas, a velocidade da água do rio é maior, a taxa de sedimentação também pode ser maior, e há maior remoção de substrato no barranco do dique, fatores que causam maior tombamento de árvores e, consequentemente, maior mortalidade (DAMASCENOJÚNIOR et al., 2004). Além disso, de acordo Appolinário et al. (2005) os sedimentos depositados nos troncos e folhas pela enchente causam limitações para o crescimento das plantas, devido à obstrução da captura de luz e trocas gasosas, afetando, principalmente, indivíduos jovens, por terem maior parte deles dentro da água, e, também, por já estarem estressados pela deficiência lumínica no sub-bosque. Assim, as baixas taxas de recrutamento podem ser explicadas na floresta ciliar pela relação com o movimento da água extravasada do rio durante as enchentes nas épocas de cheias, que dificulta o estabelecimento de plantas e aumenta a mortalidade, e nos fragmentos pelo excesso hídrico, que também diminui a sobrevivência das plantas.

As taxas de perda em área basal variaram nos estudos em florestas alagáveis, sendo de $2,92 \%$ ano ${ }^{-1}$ neste estudo, de $1,13 \%$ ano $^{-1}$ no estudo de Guimarães et al. (2008), de 0,97\% ano ${ }^{-1}$ e 3,71\% ano ${ }^{-1}$ na área de depressão e sobre o dique, respectivamente, no estudo de Guilherme et al. (2004) e de 2,8\% ano ${ }^{-1}$ no estudo de Appolinário et al. (2005). Em relação às taxas de ganho em área basal, este estudo apresentou taxas menores (2,34\% ano-1), em comparação com outros estudos de dinâmica em áreas inundáveis. A taxa de ganho do estudo de Guimarães et al. (2008) foi de 2,75\% ano-1, no estudo de Guilherme et al. (2004) as taxas foram de 10,96\% ano ${ }^{-1}$ na área de depressão e $11,71 \%$ ano $^{-1}$ na área sobre o dique, e a do estudo de Appolinário et al. (2005) foi de 3,8\% ano ${ }^{-1}$.

Segundo Barddal et al. (2004) e Appolinário et al. (2005), em condições de saturação hídrica, as árvores, normalmente, apresentam menores taxas de crescimento que em áreas bem drenadas. O ambiente anóxico ou hipóxico criado durante as enchentes, que ocasiona deficiência de $\mathrm{O}_{2}$ em nível de rizosfera, atua na diminuição da permeabilidade das raízes à água, reduzindo a absorção, o que é acompanhado pelo fechamento estomático (KOZLOWSKI; PALLARDY, 1984; LOBO; JOLY, 2000) e redução fotossintética (PEZESHKI, 1993). Esse processo, juntamente com alterações metabólicas ocasionadas pela anaerobiose, que resultam em menor produção energética (LOBO; JOLY, 2000), podendo ocasionar, também, maior consumo, ocasiona diminuição ou estagnação do crescimento dos indivíduos arbóreos ou, mesmo, o decréscimo de crescimento, durante o período de alagamento. Porém, a resposta dos indivíduos arbóreos ao encharcamento dependerá das espécies presentes na área. O estudo de Guilherme et al. (2004) apresentou alta taxa de ganho em área basal, provavelmente devido ao rápido crescimento das espécies dominantes, Salix humboldtiana e Inga vera. Segundo Lieberg e Joly (1993), o crescimento de indivíduos de Inga vera (sin. Inga affinis) sob alagamento só é menor que o de indivíduos não alagados após 80 dias de inundação. Davide et al. (1996) encontraram rápido crescimento de Salix humboldtiana, Inga vera e Sebastiania commersoniana (Baill.) L.B. Sm. \& Downs (sin. S. klotzchiana) em experimentos em área de inundação, e o crescimento de Salix humboldtiana superou o de Sebastiania commersoniana em alagamentos mais pronunciados (com até $2 \mathrm{~m}$ de coluna de água). Neste estudo, houve alta dominância e densidade de Sebastiania commersoniana, espécie que, de acordo com Kolb et al. (1998), apresenta redução no crescimento sob alagamento, que é, em parte, devido à queda no consumo de oxigênio nos primeiros dias de inundação (ROGGE et al., 1998), uma estratégia de adaptação ao ambiente alagado.

\subsection{Dinâmica da comunidade por classe diamétrica}

Os decrementos observados nas classes 1 e 4 de diâmetro ocorreram, na classe 1 , devido ao crescimento das árvores e migração para a classe 2 e, na classe 4, principalmente, pela mortalidade de alguns troncos de árvores perfilhadas. Essa mortalidade de troncos ocorreu, predominantemente, para Sebastiania commersoniana, espécie de elevada dominância e densidade na área. Foi observada a morte de vários caules, mas, de uma forma geral, os indivíduos mantêm-se vivos por brotações das cepas e ramos laterais. O perfilhamento funciona como adaptação aos ambientes 
com excesso hídrico, proporcionando aos indivíduos maior capacidade de sobrevivência. É comum observar também, nessas áreas, o tombamento de árvores mais grossas, devido à instabilidade do substrato com excesso hídrico e posterior brotações laterais da árvore tombada. Além disso, nesses ambientes perturbados pelo excesso hídrico pode estar ocorrendo a predominância da reprodução assexuada (brotação de caules e perfilhos), o que explica também o baixo recrutamento na área estudada.

Os resultados, porém, demonstraram que, seis meses após a enchente, não foi possível detectar alterações na estrutura diamétrica das áreas estudadas. Isso deve estar ocorrendo, possivelmente, porque a mortalidade de indivíduos arbóreos pode ser um processo lento (FRANKLIN et al., 1987) e, no curto prazo de avaliação após a enchente, pode não ter sido possível captar esse processo. Outra explicação seria a ocorrência proporcional de ingressos (recrutas + imigrantes) e egressos (mortos + emigrantes) em todas as classes diamétricas, não produzindo mudanças na frequência dos indivíduos nas classes de diâmetro entre os anos estudados. Segundo Damasceno Júnior et al. (2004), que também encontraram mortalidade independente da classe diamétrica em área com enchente de grandes proporções (em avaliação feita em indivíduos com DAP $>5 \mathrm{~cm}$ ), essa tendência pode ocorrer em regiões alagadas, pois o distúrbio afeta a comunidade de árvores em todas as classes diamétricas, mais ou menos na mesma intensidade.

Appolinário et al. (2005) e Guilherme et al. (2004) também encontraram mortalidade independente da classe diamétrica nas áreas inundáveis de seus estudos (DAP $>5 \mathrm{~cm}$ ). Guilherme et al. (2004) encontraram mortalidade independente da classe diamétrica somente nas áreas com influência hídrica, as áreas sem inundação tiveram mortalidade dependente da classe de diâmetro. Guimarães et al. (2008), ao contrário do padrão mais comum observado nas florestas aluviais, encontraram mortalidade de indivíduos dependente da classe diamétrica (DAP $>5 \mathrm{~cm}$ ), com a primeira classe com maior número de mortos.

\section{CONCLUSÕES}

Os resultados permitiram concluir que a dinâmica de curto prazo da comunidade arbórea dos fragmentos aluviais avaliados no Sul de Minas Gerais, após uma enchente de grandes proporções, foi caracterizada pelo desequilíbrio entre as taxas de mortalidade e de recrutamento e de ganho e perda em área basal. Essa instabilidade resultou em perda de indivíduos e em área basal, o que poderia ser uma resposta ao distúrbio ambiental causado pela enchente. No entanto, a dinâmica não ocasionou alteração na estrutura diamétrica da comunidade, pois a frequência de indivíduos sobreviventes e de mortos em 2007 nas classes diamétricas não diferiu da frequência inicial em 2005.

\section{REFERÊNCIAS}

APPOLINÁRIO, V.; OLIVEIRA FILHO, A. T.; GUILHERME, F. A. G. Tree population and community dynamics in a Brazilian tropical semideciduous forest. Revista Brasileira de Botânica, v.28, p.347-360, 2005.

BARDDAL, M. L. et al. Caracterização florística e fitossociológica de um trecho sazonalmente inundável de floresta aluvial, em Araucária, PR. Ciência Florestal, v.14, p.37-50, 2004.

BRASIL. Ministério da Agricultura e Reforma Agrária. Normais climatológicas 19611990. Brasília: 1992. 84p.

BRINSON, M. M. Reverine forests. In: LUGO, A. E.; BRINSON, M. M.; BROWN, S. (Ed.). Ecosystems of the world 15 - Forested wetlands. Amsterdam: Elsevier, 1990. p.87-141.

DAMASCENO JUNIOR, G. A. et al. Tree mortality in a riparian forest at Rio Paraguai, Pantanal, Brazil, after an extreme flooding. Acta

Botanica Brasílica, v.18, p.839-846, 2004.

DAVIDE, A. C. et al. Comportamento de espécies florestais de mata ciliar em área de depleção do reservatório da usina hidrelétrica de Camargos Itutinga, MG. Cerne, v.2, p.26-39, 1996.

FRANKLIN, J. F.; SHUGART, H. H.; HARMON, M. E. Tree death as an ecological process. BioScience, v.37, n.8, p.550-556, 1987.

GOMES, A. P. C.; SOUZA, A. L.; MEIRA-NETO, J. A. A. Alteração estrutural de uma área florestal explorada convencionalmente na Bacia do Paraíba do Sul, Minas Gerais, nos domínios de floresta atlântica. Revista Árvore, v.28, n.3, p.407-417, 2004.

Revista Árvore, Viçosa-MG, v.35, n.4, xxx-xxx, 2011 
GUILHERME, F. A. G. et al. Effects of flooding regimes and woody bamboos on tree community dynamics in a section of tropical semideciduous forest in South-Eastern Brazil. Plant Ecology, v.174, n.1, p.19-36, 2004.

GUIMARÃES, J. C. C. et al. Dinâmica do componente arbustivo-arbóreo de uma floresta de galeria aluvial no planalto de Poços de Caldas, MG, Brasil. Revista Brasileira de Botânica, v.31, n.4, p.621-632, 2008.

HIGUCHI, P. et al. Dinâmica da comunidade arbórea em um fragmento de floresta estacional semidecidual montana em Lavras, Minas Gerais, em diferentes classes de solos. Revista Árvore, v. 32, n.3,, p.417-426, 2008a.

HIGUCHI, P. et al. Spatio-temporal patterns of tree community dynamics in a tropical forest fragment in South-east Brazil. Plant Ecology, v.199, n.1, p.125-135, 2008b.

\section{FUNDAÇÃO INSTITUTO BRASILEIRO DE GEOGRAFIA E ESTATÍSTICA - IBGE. Manual técnico da vegetação brasileira. Rio de Janeiro: 1992. (Série: Manuais técnicos em geociências,.1)}

JUNK, W. J. Wetlands of tropical South America. In: WHIGHAM, D.; HEJNÝ, S.; DYKYJOVÁ, D. (Eds.). Wetlands of the world I: inventory, ecology and management. Boston: Dr. W. Junk Publishing, 1993. p.679-739.

KOLB, R. M. et al. Anatomia ecológica de Sebastiania commersoniana (Baillon) Smith \& Downs (Euphorbiaceae) submetida ao alagamento. Revista Brasileira de Botânica, v.21, n.3, p.305-312, 1998.

KORNING, J.; BALSLEV, H. Growth and mortality of trees in Amazonian tropical rain forest in Ecuador. Journal of Vegetation Science, v.4, n.1, p.77-86, 1994.

KOZLOWSKI, T. T.; PALLARDY, S. G. Effect of flooding on water, carbohydrate, and mineral relations. In: KOSLOWSKI, T. T. (Ed.). Flooding and plant growth. London: Academic Press, 1984. p.129-163.
LIEBERG, S. A.; JOLY, C. A. Inga affinis DC (Mimosaceae): germinação e tolerância de plântulas à submersão. Revista Brasileira de Botânica, v.16, n.1, p.175-179, 1993.

LIEBERMAN, D. et al. Mortality patterns and stand turnover rates in a wet tropical forest in Costa Rica. Journal of Ecology, v.73, n.3, p.915-924, 1985.

LOBO, P. C.; JOLY, C. A. Aspectos ecofisiológicos da vegetação de mata ciliar do Sudeste do Brasil. In: RODRIGUES R. R.; LEITÃO FILHO, H. F. (Eds.). Matas ciliares: conservação e recuperação. São Paulo: EDUSP, 2000. p.143-157.

MACHADO, E. L. M.; OLIVEIRA-FILHO, A. T. Spatial patterns of tree community dynamics are detectable in a small (4 ha) and disturbed fragment of the Brazilian Atlantic forest. Acta Botanica Brasilica, v.24, n.1, p.250-261, 2010.

OLIVEIRA FILHO, A. T.; MELLO, J. M.; SCOLFORO, J. R. Effects of past disturbance and edges on tree community structure and dynamics within a fragment of tropical semideciduous forest in south-eastern Brazil over a five years period (1987-1992). Plant Ecology, v.131, n.1, p.45-66, 1997.

OLIVEIRA FILHO, A. T. et al. Dinâmica da comunidade e populações arbóreas da borda e interior de um remanescente florestal na Serra da Mantiqueira, Minas Gerais, em um intervalo de cinco anos (1994 - 2004). Revista Brasileira de Botânica, v.30, n.1, p.149-161, 2007.

PEZESHKI, S. R. Differences in patterns of photosynthetic responses to hypoxia in floodtolerant and flood-sensitive tree species. Photosynthetica, v.28, n.3, p.423-430, 1993.

R DEVELOPMENT CORE TEAM. R: A language and environment for statistical computing. $\mathrm{R}$ Foundation for Statistical Computing, Vienna, 2005. Disponível em <http://www.R-project.org> Acesso em: 20 maio de 2008.

RIZZINI, C. T. Tratado de fitogeografia do Brasil: aspectos ecológicos, sociológicos e florísticos. Rio de Janeiro: Âmbito Cultural Edições, 1997. 747p. 
ROGGE, G. D. et al. Metabolismo respiratório de raízes de espécies arbóreas tropicais submetidas à inundação. Revista Brasileira de

Botânica, v.21, n.2, p.153-158, 1998.

SHEIL, D.; MAY, R. M. Mortality and recruitment rate evaluations in heterogeneous tropical forests. Journal of Ecology, v.84, n.1, p.91-100, 1996.

SHEIL, D.; JENNINGS, S.; SAVILL, P. Long-term permanent plot observations of vegetation dynamics in Bundongo, a Ugandan rain forest. Journal of Tropical Ecology, v.16, n.6, p.675-800, 2000.

SILVA, A. C. et al. Florística e estrutura da comunidade arbórea em fragmentos de Floresta Aluvial em São Sebastião da Bela Vista, Minas Gerais. Revista Brasileira de Botânica, v.32, n.2, p.283-297, 2009.
SILVA, A. C.; HIGUCHI, P.; van den BERG, E. Effects of soil water table regime on tree community species richness and structure of alluvial forest fragments in Southeast Brazil. Brazilian Journal of Biology, v.70, n.3, p.465-471, 2010.

SOKAL, R. R.; ROHLF, F. J. Biometry: the principles and practice of statistics in biological research. 3.ed. New York: WH Freeman Company, 1994.

STATSOFT, INC. STATISTICA. Data analysis software system, version 6, 2001. Disponível em <http://www.statsoft.com> Acesso em: 20 maio de 2008.

SWAINE, M. D.; LIEBERMAN, D.; PUTZ, F. E. The dynamics of tree populations in tropical forest: a review. Journal of Tropical Ecology, v.3, n.3, p.359-366, 1987. 
